\title{
Developmental Psychology, Adolescence
}

National Cancer Institute

\section{Source}

National Cancer Institute. Developmental Psychology, Adolescence. NCI Thesaurus.

Code C18737.

Developmental psychology research focusing on the adolescent years. 